\title{
Effect of increasingly metallized hybrid reinforcement on the wear mechanisms of magnesium nanocomposite
}

\author{
S FIDA HASSAN ${ }^{1, *}$, A M AL-QUTUB ${ }^{1}$, S ZABIULLAH ${ }^{1}$, K S TUN ${ }^{2}$ and M GUPTA ${ }^{3}$ \\ ${ }^{1}$ Department of Mechanical Engineering, King Fahd University of Petroleum \& Minerals, P.O. Box 1061, Dhahran 31261, \\ Kingdom of Saudi Arabia \\ ${ }^{2}$ Technology Development Centre, ITE College Central, Singapore 567720, Singapore \\ ${ }^{3}$ Department of Mechanical Engineering, National University of Singapore, Singapore 117576, Singapore
}

MS received 21 December 2014; accepted 8 February 2016

\begin{abstract}
Strength and ductility of pure magnesium have experienced simultaneous improvement due to the presence of nanosize hybrid (yttria and copper) reinforcement. Increasing the vol\% (i.e., 0.3-1.0) of ductile metallic copper particles in reinforcement has further enhanced the strength of magnesium. Wear behaviour of these magnesium hybrid nanocomposites was investigated using pin-on-disc dry sliding tests against hardened tool steel using a constant sliding speed of $1 \mathrm{~m} \mathrm{~s}^{-1}$ under a range of loads from 5 to $30 \mathrm{~N}$ for a sliding distance of $1000 \mathrm{~m}$. Scanning electron microscopy identified abrasion and delamination as primary wear mechanisms in the hybrid nanocomposite. Oxidation was active in nanocomposite with higher copper content, tested under higher load and positively affected the wear resistance. Limited thermal softening was observed when tested at a relatively higher load. High frictional heat dissipation capacity couples with higher hardness resisted adhesive wear which is common mechanism for magnesium composite.
\end{abstract}

Keywords. Metal-matrix composite; wear testing; sliding wear; electron microscopy.

\section{Introduction}

Ever growing demand of light-weight structural materials from consumer industries like automobile and aerospace, for energy conservation and environmental protection brought low-density magnesium-based materials into centre of attention [1-3]. However, relatively lower strength and ductility in addition to poor thermal stability, corrosion and wear resistance restricts wide range of genuine industrial applications of magnesium alloys. There is an extensive effort in recent times for finding alternative ways to overcome these inherent limitation of magnesium-based materials to an extent exceeding the range achieved by traditional alloying. Competence of nanometre size oxide ceramic reinforcement in simultaneous enhancement of strength, ductility and thermal stability of magnesium [1,4-8] ushered a potential new generation of light-weight structural materials for wider industrial applications. Alumina and yttria were found to be the most effective oxide ceramics in improving the required structural properties of magnesium when incorporated in nanosize as a reinforcement. However, the structural properties of magnesium, despite significant enhancement due to the presence of nanosize oxide ceramic reinforcement, are in need of further improvement for an extensive application as substitute

\footnotetext{
*Author for correspondence (sfhassan@kfupm.edu.sa, itsforfida@gmail.com)
}

of the existing structural materials. High melting point ductile metal as copper have strong strengthening effect on magnesium matrix when added as reinforcement [9] rather than alloying element. Copper has a much larger atomic size and different crystal structures and extremely negligible solubility in magnesium [10]. The limited reactivity between copper reinforcement and magnesium matrix is advantageous to produce good matrix-reinforcement interfacial integrity and to introduce stronger intermetallic phase in magnesium matrix. Understanding the effectiveness of oxide ceramic and relatively high-melting point metallic reinforcement on magnesium matrix has inspired in the development of hybrid reinforcement incorporated magnesium nanocomposite [11] with interestingly higher strength and ductility. Application of this newly developed high-performance light-weight structural hybrid nanocomposite will involve many challenges including understanding the wear behaviour against any moving counterface. Search in open literature has revealed only our earlier report [12], which discussed the wear mechanisms involved in one of these magnesium nanocomposite with $0.3 \mathrm{vol} \%$ copper containing hybrid nanoreinforcement particles. However, no work has been reported on the wear behaviour analysis to understand the stability and longevity of these hybrid nanocomposites with varying amount of metallic copper. Accordingly, this paper presents a study on the wear characteristics of magnesium hybrid nanocomposites containing nanosize reinforcement of yttria and copper in dry sliding condition against a hardened tool steel counterface. 


\section{Experimental}

\subsection{Materials}

In this present study, magnesium powder with $98.5 \%$ purity and a size range of 60-300 $\mu \mathrm{m}$ (Merck, Germany) was used as matrix material. Yttria $\left(\mathrm{Y}_{2} \mathrm{O}_{3}\right)$ with a particulate size range of 30-50 nm (Inframat Advanced Materials, USA) and pure copper $(\mathrm{Cu})$ with an average particulate size of $25 \mathrm{~nm}$ (Nanostructured and Amorphous Materials Inc., USA) were used as reinforcements.

In total, 0.7 vol\% of yttria (selected based on the optimization obtained in previous studies $[5,7]$ ) in combination with $0.3,0.6$ and 1.0 vol\% of copper was used as hybrid reinforcement in this study. The powder metallurgy synthesis procedure of $\mathrm{Mg} /\left(0.7 \mathrm{Y}_{2} \mathrm{O}_{3}+\mathrm{Cu}\right)$ hybrid nanocomposite involved blending pure magnesium powder with nanosized reinforcement powder in a mechanical alloying machine (model: RETSCH PM-400) at $200 \mathrm{rev} \mathrm{min}^{-1}$ for $1 \mathrm{~h}$ (60 min). The blended powder mixtures were subsequently cold compacted at a pressure of 97 bar using a 100 ton press to form billets that measured $35 \mathrm{~mm}$ in diameter and $40 \mathrm{~mm}$ in height. The compacted billets were immediately sintered using an innovative hybrid microwave sintering technique [11] for 13 min to reach a temperature $\left(643^{\circ} \mathrm{C}\right)$ near the melting point of magnesium using a $900 \mathrm{~W}, 2.45 \mathrm{GHz}$ SHARP microwave oven. The sintered billets were subsequently hot extruded at a temperature of $350^{\circ} \mathrm{C}$ at an extrusion ratio of $25: 1$.

Physical, microstructural and mechanical properties of the developed hybrid nanocomposite were performed and the findings are tabulated in table 1. Further details of fabrication process and characterization studies of the hybrid nanocomposite may be found elsewhere [11].

\subsection{Microhardness test}

Microhardness measurements were performed on the polished specimens of hybrid nanocomposites using a Matsuzawa MXT 50 automatic digital microhardness tester. The microhardness test was performed using a Vickers indenter under a test load of $25 \mathrm{gf}$ and a dwell time of $15 \mathrm{~s}$ in accordance with the ASTM standard E384-10.

\subsection{Wear test}

Ambient temperature dry sliding wear tests of the hybrid nanocomposites were conducted using a pin-on-disc testing machine. Pin specimens were machined from as-extruded hybrid nanocomposite rods with a dimension of $6 \mathrm{~mm}$ in diameter and $15 \mathrm{~mm}$ in length. Contact surfaces on the pins were prepared by grinding against 600-grit silicon carbide paper and cleaning with alcohol. Customized pin-holder loaded each of the stationary pins vertically onto a rotating AISI-4140 tool-steel disc, which was earlier oil-hardened to 53 HRC.

Wear tests were conducted at a constant sliding speed of $1 \mathrm{~m} \mathrm{~s}^{-1}$ under six different loads (i.e., 5, 10, 15, 20, 25 and $30 \mathrm{~N}$ ). For each of the sliding condition, individual hybrid nanocomposite pin had five runs of $1000 \mathrm{~m}$ each. Prior to every run, the tool steel disc counterface was ground with alumina abrasive wheel to a surface finish with an average $R_{\mathrm{a}}$ value of approximately $0.3 \mu \mathrm{m}$ followed by cleaning with alcohol. The grinding procedure was to remove accumulated debris on the wear track from earlier test run. At the end of each run, the pins were carefully cleaned with alcohol and weighed using a sensitive electronic balance with an accuracy of $\pm 0.005 \mathrm{mg}$ to determine the weight loss. Material had been extruded from the pin surface and later re-solidified around the periphery, especially under higher loading. Since these extruded layers should be considered as material worn, they were carefully filled off prior to weighing so as not to add falsely to the weight. All weight loss data were converted to volume loss using the measured densities. The worn pin surfaces and wear debris collected were examined and analysed using scanning electron microscopy (SEM) and energy-dispersive X-ray spectroscopy (EDS).

\section{Results and discussion}

\subsection{Microhardness}

Results of microhardness measurement revealed that there is an increase in the hardness of hybrid nanocomposites with the increase in copper vol\% (see table 2) with a linear relationship between microhardness of hybrid nanocomposite and copper content (see figure 1a). Increment in the microhardness can primarily attributed to the increasing presence of copper particles (including $\mathrm{Mg}-\mathrm{Cu}$ intermetallic) which is stiffer (44.7 GPa for magnesium [13], 171.5 GPa for $\mathrm{Y}_{2} \mathrm{O}_{3}$ [14] and 129.8 GPa for copper [13]) with lower coefficient of thermal expansion, which is $28.9 \times 10^{-6} \mathrm{~K}^{-1}$ for magnesium [13], $7.6 \times 10^{-6} \mathrm{~K}^{-1}$ for $\mathrm{Y}_{2} \mathrm{O}_{3}$ [14] and $18.3 \times 10^{-6}$ $\mathrm{K}^{-1}$ for copper [13].

Table 1. Some properties of the hybrid nanocomposites pin specimens used in this study [11].

\begin{tabular}{|c|c|c|c|c|c|c|c|}
\hline Material & $\begin{array}{l}\text { Density } \\
\left(\mathrm{g} \mathrm{cm}^{-3}\right)\end{array}$ & $\begin{array}{c}\text { Grain } \\
\text { size }(\mu \mathrm{m})\end{array}$ & $\begin{array}{l}\text { Porosity } \\
(\text { vol } \%)\end{array}$ & $\begin{array}{l}0.2 \% \mathrm{YS} \\
(\mathrm{MPa})\end{array}$ & $\begin{array}{l}\text { Ultimate tensile strength } \\
\qquad(\mathrm{MPa})\end{array}$ & Ductility (\%) & $\begin{array}{c}\text { Energy absorbed } \\
\left(\mathrm{MJ} \mathrm{m}^{-3}\right)\end{array}$ \\
\hline $\mathrm{Mg}$ & 1.738 & 20 & 0.35 & 134 & 193 & 6.9 & 12.9 \\
\hline $\mathrm{Mg} / 0.7 \mathrm{Y}_{2} \mathrm{O}_{3}+0.3 \mathrm{Cu}$ & 1.775 & 9 & 0.45 & 215 & 270 & 11.1 & 29.8 \\
\hline $\mathrm{Mg} / 0.7 \mathrm{Y}_{2} \mathrm{O}_{3}+0.6 \mathrm{Cu}$ & 1.792 & 9 & 0.77 & 179 & 231 & 11.1 & 25.4 \\
\hline $\mathrm{Mg} / 0.7 \mathrm{Y}_{2} \mathrm{O}_{3}+1.0 \mathrm{Cu}$ & 1.825 & 8 & 0.83 & 148 & 200 & 10.2 & 20.3 \\
\hline
\end{tabular}


Table 2. Microhardness of hybrid nanocomposite pin specimens.

\begin{tabular}{lc}
\hline Material & Microhardness (HV) \\
\hline $\mathrm{Mg}[7]$ & 37 \\
$\mathrm{Mg} / 0.7 \mathrm{Y}_{2} \mathrm{O}_{3}+0.0 \mathrm{Cu}[7]$ & 45 \\
$\mathrm{Mg} / 0.7 \mathrm{Y}_{2} \mathrm{O}_{3}+0.3 \mathrm{Cu}$ & 55 \\
$\mathrm{Mg} / 0.7 \mathrm{Y}_{2} \mathrm{O}_{3}+0.6 \mathrm{Cu}$ & 58 \\
$\mathrm{Mg} / 0.7 \mathrm{Y}_{2} \mathrm{O}_{3}+1.0 \mathrm{Cu}$ & 62 \\
\hline
\end{tabular}

\subsection{Wear rates}

The volumetric wear rates of the hybrid nanocomposites with increasing copper vol\% against load are plotted in figure $1 \mathrm{~b}$, which revealed a gradual increase in materials removal from the hybrid nanocomposites pin with the increase in experimental load with a constant sliding speed. The results revealed that there is marginal improvement in wear resistance in the hybrid nanocomposites with the increase in copper vol\% when tested within a limit of 15-25 $\mathrm{N}$ test load. At test load below and above this boundary limit, increasing presence of copper does not play any observable role in cumulative wear resistance in the developed hybrid nanocomposites.

\subsection{Wear mechanisms}

SEM on the worn specimen surfaces of the tested hybrid nanocomposites with the increase in copper vol\% revealed four different wear mechanisms operating, either singly or in
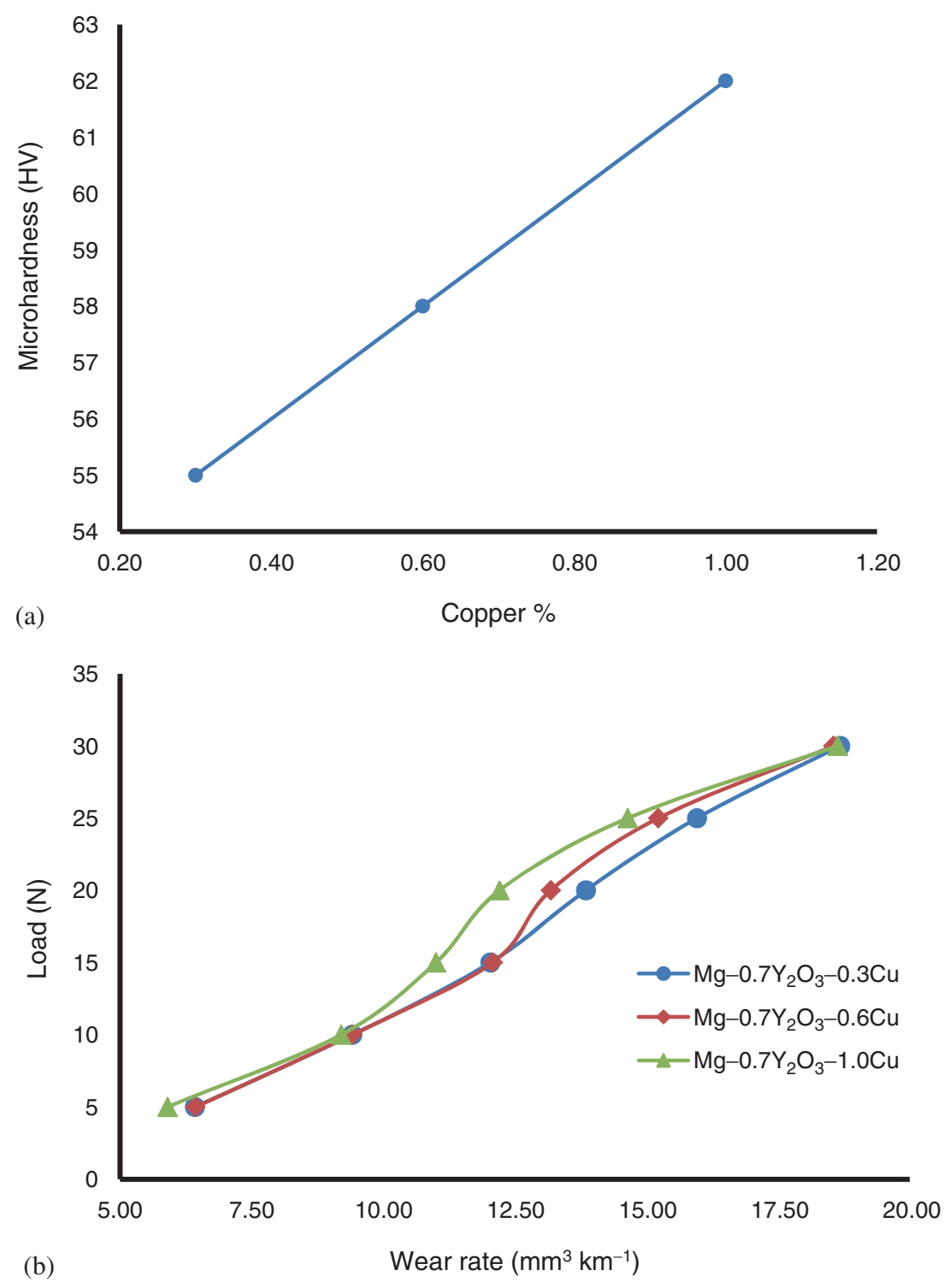

Figure 1. Graphs showing relationship between: (a) microhardness and copper vol\% and (b) wear rate and applied load on hybrid nanocomposite pins during dry sliding against a hardened tool steel disc. 
combination, under the various sliding conditions. The wear mechanisms were identified as (i) abrasion, (ii) delamination, (iii) oxidation, (iv) thermal softening and (v) adhesion. In the following sections, the observed wear mechanisms are discussed in relation to the sliding conditions, wear rates and increasing presence of copper particles to better understand the tribological characteristics and identify the useful range of applications for these hybrid nanocomposites.

3.3a Abrasion: All the worn specimen surfaces of the hybrid nanocomposites with the increase in vol\% of copper particle were covered with grooves parallel to the sliding direction (see figure $2 \mathrm{a}$ ), which is associated with abrasive wear [15]. Hard asperities on the tool steel counterface disc in addition to the hard particles between the specimen and rotating steel counterface disc plough or cut into the specimen surface and resulted in wear by removal of small fragments of hybrid composite materials. Increased test load used in this study induced grooves of different extent, from well-defined deep grooves to shallower scratches accompanied by increasing amount of plastic deformation (see figure $2 \mathrm{~b}$ ). Higher degree of penetration by hard asperities of hardened tool steel counter surface induced the deep grooves, with minimal displacement of materials on both sides in the matrix materials suggesting abrasion as a primary wear mechanism for the hybrid nanocomposite under the load range used in this study. However, abrasion wear mechanism was found to have relatively lesser dominating on the matrix material when containing 1.0 vol\% of copper and

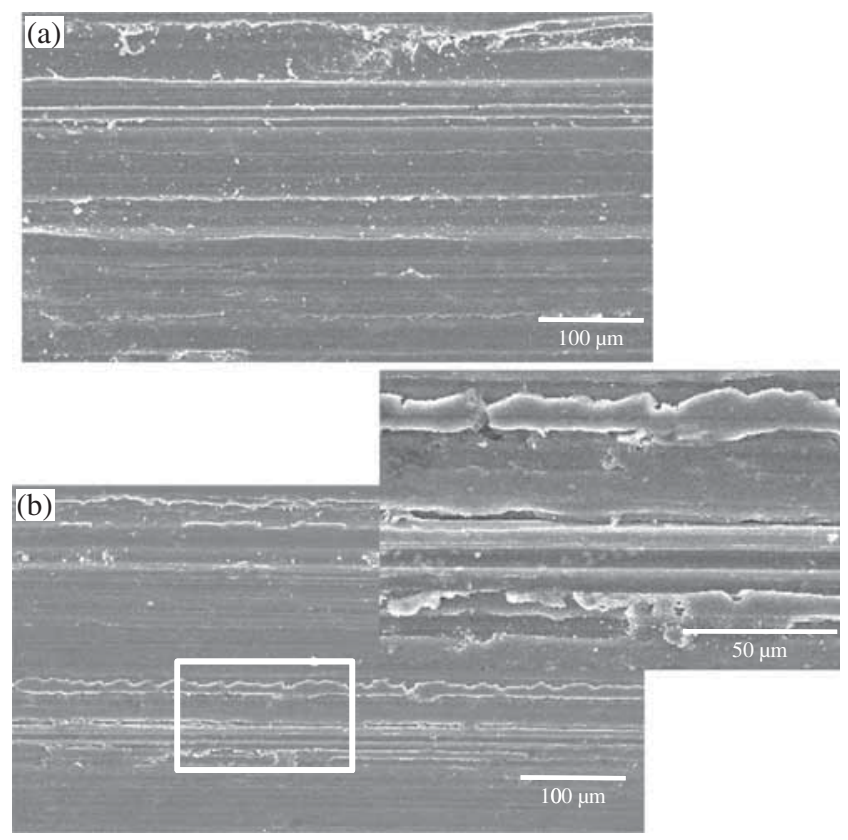

Figure 2. Scanning electron micrographs showing: (a) grooves and scratch marks indicating abrasion (in $\mathrm{Mg} / 0.7 \mathrm{Y}_{2} \mathrm{O}_{3}+0.3 \mathrm{Cu}$ under $5 \mathrm{~N}$ ) and (b) shallow grooves with plastic deformation (in $\mathrm{Mg} / 0.7 \mathrm{Y}_{2} \mathrm{O}_{3}+0.6 \mathrm{Cu}$ under $\left.10 \mathrm{~N}\right)$. could be attributed to the higher hardness of that nanocomposite. Dominating role of abrasion as wear mechanism in this study is in agreement with findings of earlier studies reported on the wear of magnesium alloy reinforced with extremely fine ceramic particle reinforcement $[16,17]$.

3.3b Delamination: Worn hybrid nanocomposite surfaces revealed short cracks roughly perpendicular to the sliding direction (see figure 3a), which is associated with delamination wear [17-19]. Intersection of these short cracks resulted in detachment of specimen materials in flake or sheet-like wear debris and leaves behind shallow craters on the wear surface (see figure $3 b$ ). Delamination is a fatigue-related wear mechanism [20] in which the repeated sliding between
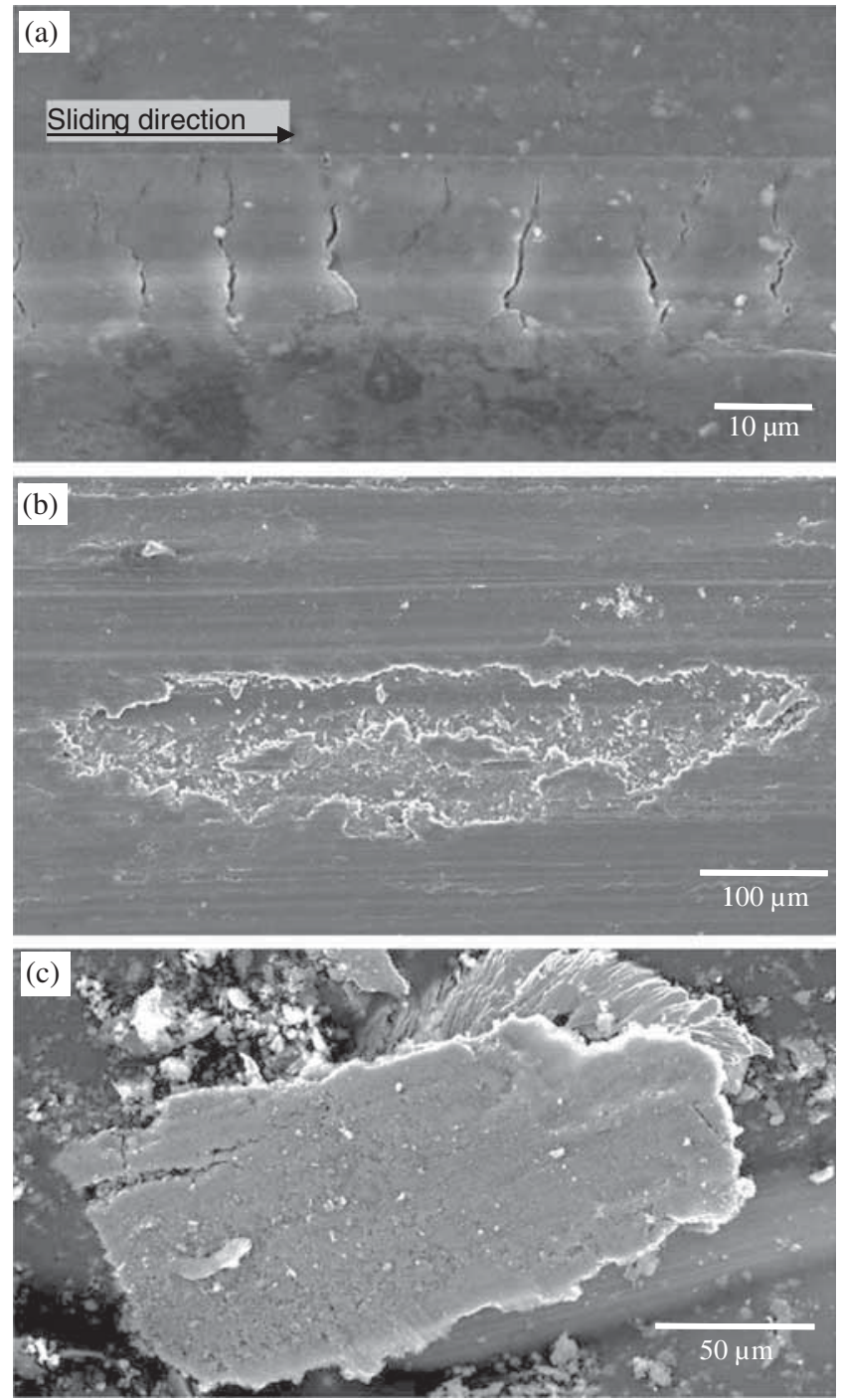

Figure 3. Scanning electron micrographs showing $\mathrm{Mg} / 0.7 \mathrm{Y}_{2} \mathrm{O}_{3}+$ $0.6 \mathrm{Cu}$ under $25 \mathrm{~N}$ : (a) series of fine cracks perpendicular to the sliding direction on the specimen surface, generally associated with delamination, (b) shallow crater on the specimen surface, where thin sheets of material have been worn away by delamination and (c) flake- or sheet-like wear debris typical of delamination. 
the counter bodies induces subsurface cracks, which progressively grows resulting in eventual shear off the surfaces in long thin wear flake or sheets form. Hence, materials with low toughness (see table 1) supposedly affected much by the delamination wear mechanism as revealed in this study. Load required for initiation of delamination in the hybrid nanocomposite was found to be increasing with the increase in copper particles (i.e., from $10 \mathrm{~N}$ for nanocomposite with $0.3 \mathrm{vol} \%$ of copper to $20 \mathrm{~N}$ for nanocomposite with 1.0 vol\% of copper). Again, increasing test load was found to be increasing the amount of delamination in the hybrid nanocomposite specimens. Increasing test load incurred enhanced subsurface deformation, crack nucleation and crack propagation [20] in the hybrid nanocomposite leading to higher wear (see figure 1). Despite having highest hardness (see table 2), hybrid nanocomposite with 1.0 vol\% of copper suffered increasingly severe delamination when subjected to higher test load $(25-30 \mathrm{~N})$, which could be attributed to easy initiation and propagation of cracks due to the presence of relatively higher porosity (see table 1). Findings on the effect of delamination on the magnesium hybrid nanocomposite used in this study are similar to the earlier published reports [19-21].

3.3c Oxidation: SEM revealed that increasing amount of fine powder present in the wear debris with the increase in test load (see figure 4a), in the case of nanocomposites containing copper particles of 0.6 vol\% and above and tested at $10 \mathrm{~N}$. EDS identified strong oxygen and magnesium
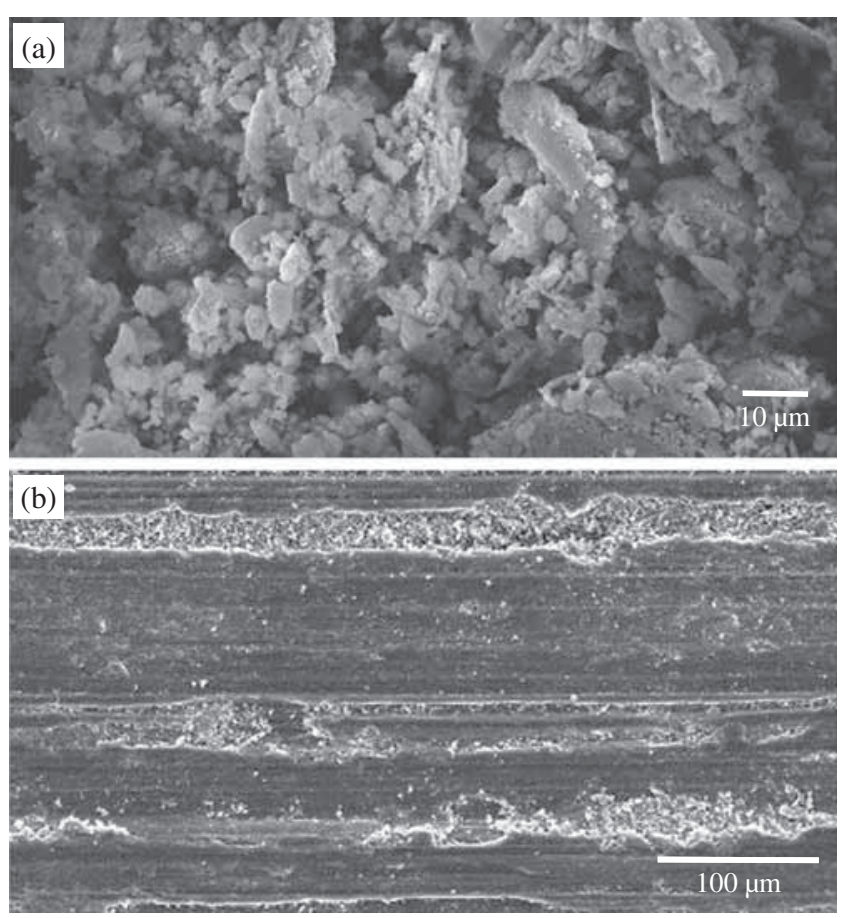

Figure 4. Scanning electron micrographs showing $\mathrm{Mg} / 0.7 \mathrm{Y}_{2} \mathrm{O}_{3}+$ $1.0 \mathrm{Cu}$ under $25 \mathrm{~N}$ : (a) oxide in wear debris and (b) compacted oxide particles in wear grooves. peaks suggesting that the wear debris consists of magnesium oxides, which is characteristic of oxidative wear. Frictional heating during sliding causes oxidation of the specimen surface and the wear occurs through the removal of oxide fragments [21]. Over-repeated sliding, oxide wear debris fills out the valleys on the pin surface as seen in figure $4 \mathrm{~b}$, which may become compacted protective layer to prevent metallic contact resulting in the wear rates drop (see figure 1b) accordingly [22]. Oxidation continues with increasing testing load and improved the wear resistance.

3.3d Extrusion wear: Thermal softening and localized melting (see figure 5a) induced extrusion wear [23] of the worn hybrid nanocomposites specimen surfaces became evident with slightly protruding layers of materials at the trailing edge (see figure 5b), when tested under load of $15 \mathrm{~N}$ and above in this study. The worn surface also found to be relatively featureless accompanied by larger amount of material transfer on the counter steel disc. Relatively less thermal softening was observed in the case of hybrid nanocomposite with 1.0 vol\% of copper and could be attributed to their capability of proportionately higher frictional heat dissipation capacity. Previous study on nanocomposite also reported similar relatively less thermal softening [16].

3.3e Adhesion: Adhesive wear mechanism considered to be dominant in the wear of magnesium-based composite materials $[16,17]$ which is almost absent in the case of hybrid
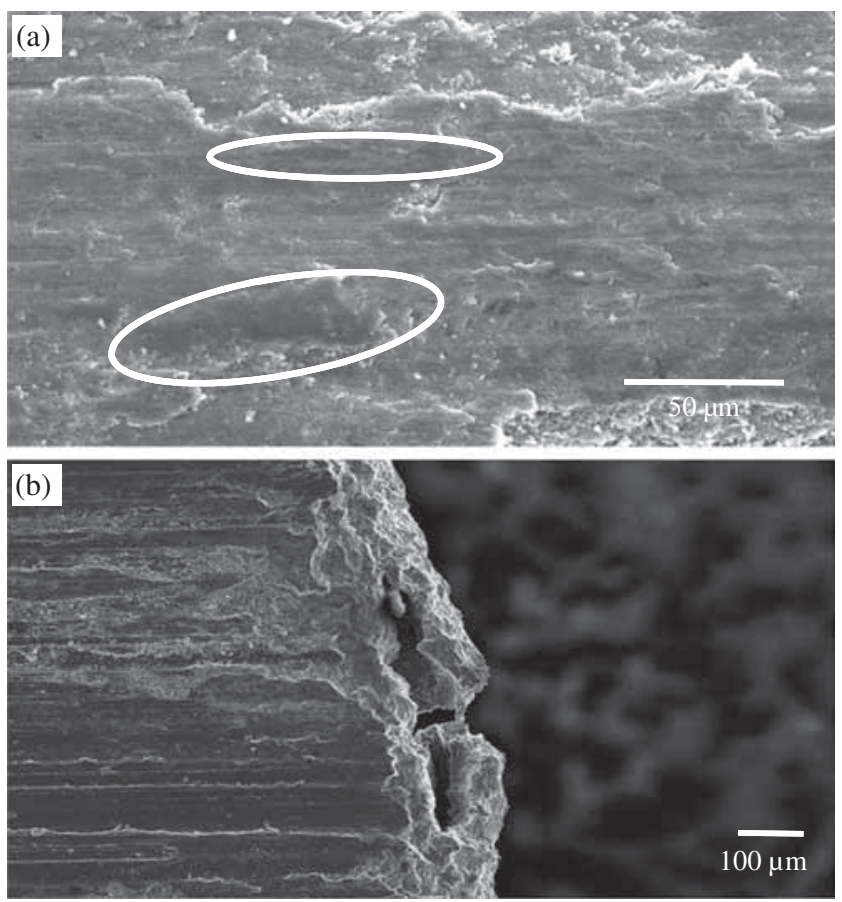

Figure 5. Scanning electron micrographs showing: (a) featureless re-solidified materials in $\mathrm{Mg} / 0.7 \mathrm{Y}_{2} \mathrm{O}_{3}+0.6 \mathrm{Cu}$ under $25 \mathrm{~N}$ and (b) extruded layers at the trailing edge in $\mathrm{Mg} / 0.7 \mathrm{Y}_{2} \mathrm{O}_{3}+0.3 \mathrm{Cu}$ under $20 \mathrm{~N}$. 

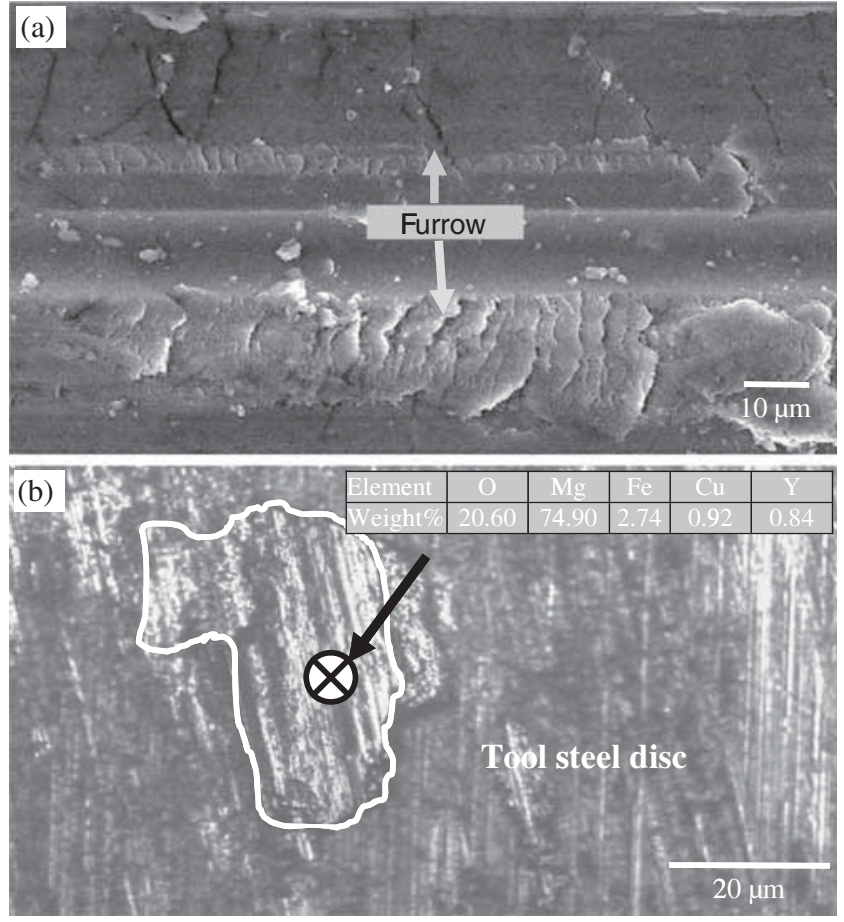

Figure 6. Scanning electron micrographs showing adhesion associated: (a) rows of furrows and (b) transferred material in the case of $\mathrm{Mg} / 0.7 \mathrm{Y}_{2} \mathrm{O}_{3}+0.3 \mathrm{Cu}$ samples under $30 \mathrm{~N}$ load.

nanocomposites tested in this study. Onset of adhesive wear was observed only in hybrid nanocomposite with $0.3 \mathrm{vol} \%$ of copper when tested under $30 \mathrm{~N}$ load. There was induction of rows of furrows and sign of plastic deformation (see figure $6 \mathrm{a}$ ) on the specimen surface accompanied by distinct transferred materials (see figure 6b) covered wear track on the counter tool steel disc. Frictional heating at this loading condition apparently led to the threshold softening of the hybrid nanocomposite, with lowest amount of copper required for initiating the adhesion between the pin and disc. The presence of increased copper apparently dissipate the frictional heat effectively from the specimen frictional surface and resist this detrimental wear mechanism.

\subsection{Summary of wear behaviour}

Five different wear mechanisms were found to be active in the wear of hybrid (ceramic and metallic) nanocomposite containing increasing amount of copper particles when studied using a constant sliding speed $1 \mathrm{~m} \mathrm{~s}^{-1}$ under a range of loads from 5 to $30 \mathrm{~N}$ for a sliding distance of up to $1000 \mathrm{~m}$. The various wear mechanisms and their region of dominance in the hybrid nanocomposite were defined by the load and copper content as summarized and shown in figure 7, where transition from one group of wear mechanisms to another are apparently gradual and separated with approximate boundaries. At lowest testing load used in this study (i.e., $5 \mathrm{~N}$ ), abrasion is the only wear mechanism for the hybrid nanocomposites and has diminishing effect (see

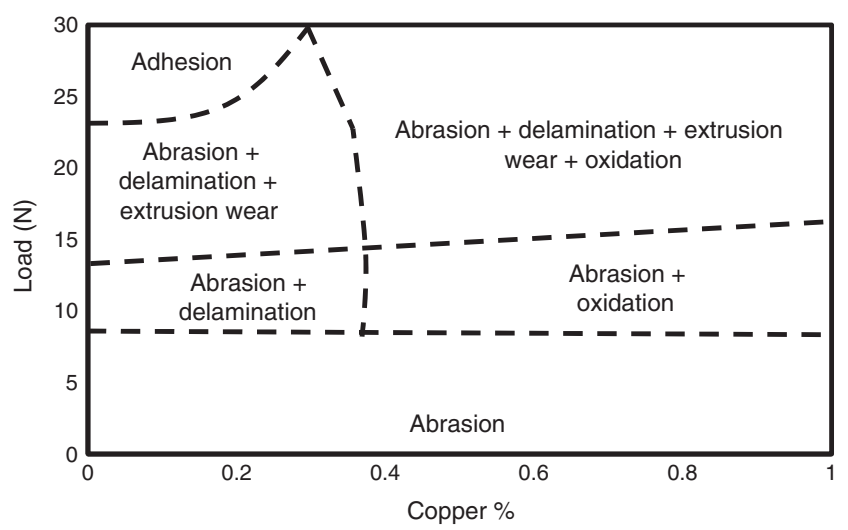

Figure 7. Diagram illustrating the conditions and approximate boundaries of dominance of the five wear mechanisms identified in the present study.

figure 1), when the hardness of the matrix increased due to the presence of higher copper content. Delamination wear mechanism came into effect, in addition to abrasion, when the test load is increased to $10 \mathrm{~N}$ and its dominance as wear mechanism in hybrid nanocomposite increased with increasing test load. However, load required to induce the delamination is increased to $15 \mathrm{~N}$, when there is an increase in copper content in the nanocomposite. Cumulative effect of abrasion and delamination led to the progressive wear in the hybrid nanocomposite (see figure 1). Oxidation as wear mechanism was increasingly visible in the nanocomposites containing copper particle of $0.6 \mathrm{vol} \%$ and above when tested under load on $10 \mathrm{~N}$ and above, which restricted specimen surface contact with hardened tool steel counterface resulting improved wear resistance (see figure 1b). However, intensively increasing delamination in nanocomposite with relatively higher porosity due to addition of increasing copper reinforcement particle diminished the absolute wear resistance at higher load which also revealed the useful limit of load for these materials. The increase in test load at $15 \mathrm{~N}$ and above (in the case of nanocomposite with $1.0 \mathrm{vol} \%$ of copper particle) induced thermally activated thermal softening. Thermal softening continued with the increase in loading till the limit used in this study. Findings of this study is corroborating with earlier reports on thermal softening resistance of magnesium composite [16,17]. Transition from delamination dominance to adhesive wear was restricted only in the nanocomposite with $0.3 \mathrm{vol} \%$ of copper tested at $30 \mathrm{~N}$ load. However, higher hardness of the nanocomposites due to the presence of increased copper particles improved the matrix load-bearing capacity resulting strong resistance to adhesive wear.

\section{Conclusions}

Pin-on-disc dry sliding wear tests with pins of magnesiumbased hybrid $\left(0.7 \mathrm{Y}_{2} \mathrm{O}_{3}+0.3-1.0 \mathrm{Cu}\right)$ nanocomposite against a tool steel counterface were carried out using a constant 
sliding speed of $1 \mathrm{~m} \mathrm{~s}^{-1}$ under a range of loads from 5 to $30 \mathrm{~N}$ for a sliding distance of $1000 \mathrm{~m}$. Abrasion and delamination were found to be the most dominant wear mechanisms. Oxidation was active in nanocomposite, with higher copper content ( 0.6 and above), tested under higher load and positively affected the wear resistance. Limited thermal softening was observed in the nanocomposites when tested at relatively higher load. Adhesive wear mechanism, most common in magnesium composite, was found to be almost absent in these hybrid nanocomposite due to their apparent increased heat dissipation capacity and high load bearing capacity induced by the increasing presence of copper particles.

\section{Acknowledgement}

We would like to acknowledge the support provided by the Deanship of Scientific Research (DSR) at King Fahd University of Petroleum and Minerals (KFUPM) for funding this work through project no. SB100020.

\section{References}

[1] Kainer K U 2003 Magnesium alloys and technology (Weinhei: Wiley-VCH Verlag GmbH and Co., KGaA)

[2] Logan S 2007 Magnesium technology In: The minerals, metals and materials society (eds) S Randy et al (Orlando: Wiley and Sons) p 41
[3] Ye H Z and Liu X Y 2004 J. Mater. Sci. 396153

[4] Hassan S F and Gupta M 2005 Metall. Mater. Trans. A 36 2253

[5] Hassan S F and Gupta M 2007 J. Alloys Compd. 429176

[6] Hassan S F, Tan M J and Gupta M 2008 Mater. Sci. Eng. A 48656

[7] Tun K S and Gupta M 2007 Comp. Sci. Technol. 672657

[8] Mallick A et al 2010 J. Mater. Sci. 453058

[9] Hassan S F and Gupta M 2003 Mater. Sci. Technol. 19253

[10] Nayeb-Hashemi A A and Clark J B 1984 Bull. Alloy Phase Diagr. 536

[11] Tun K S, Gupta M and Srivatsan T S 2010 Mater. Sci. Technol. 2687

[12] Hassan S F et al 2015 J. Tribol. 137 011601-1 (4 pages)

[13] Smallman R E 1970 Modern physical metallurgy 3rd edn (London: Butterworth)

[14] Morrell R 1985 Handbook of properties of technical and engineering ceramics (London: HMSO)

[15] Hokkirigawa K and Kato K 1988 Tribol. Int. 21151

[16] Lim C Y H et al 2005 Wear 259620

[17] Lim C Y H, Lim S C and Gupta M 2003 Wear 255629

[18] Sharma S C, Anand B and Krishna M 2000 Wear 24133

[19] Chen H and Alpas A T 2000 Wear 246106

[20] Suh N P 1977 Wear 441

[21] Quinn T J F 1962 Br. J. Appl. Phys. 1333

[22] Stott F H and Wood G C 1978 Tribol. Int. 11211

[23] So H, Chen H M and Chen L W 2008 Wear 2651142 